Ma. Josefa P.W. de Tamburini

\title{
LACLOS Y LA REVOLUCIÓN
}

Les liaisons dangereuses tiene, con su publicación, un enorme suceso, "suceso de escándalo" para algunos. Sin embargo, después de Baudelaire, la crítica inició la búsqueda de las causas de la fascinación ejercida por esta novela.

La vida de Choderlos de Laclos no se parece en nada a la de su héroe Valmont. De guarnición en guarnición, llega a capitán, el grado más alto al que sus orígenes le permitían ac ceder. En 1786 su Lettre sur l'eloge de Vauban (panfleto y proyecto de defensa modernista), le vale el exilio a Toul.

Militante burgués desde los primeros días de la Revolución, promovido a general después de Valmy, hecho prisionero luego, debe su salvación a la caída de Robespierre el 9 Thermi dor. Muere en Tarento, como general del Imperio, en 1803.

Pero no son los hechos militares los que hacen su celebridad sino la publicación, en 1782 , de su novela epistolar. Más de cincuenta ediciones se suceden hasta 1815 .

Lejos de enmascarar la realidad, perdiéndose en temas diversos, las cartas sirven para reforzarla. No es Laclos el que habla sino cada uno de sus interlocutores, en su propio lenguaje. Son tan variadas como los diferentes caracteres de los personajes. Son, también, igualmente veraces, igualmente originales.

El escritor muestra asi, de manera implacable, un "mundo", y analiza con asombrosa lucidez lo que Roger Vailland, en su obra Laclos par lui-même, llama el juego dramático de los libertinos.

Las relaciones de los dos maestros en libertinaje, Mada- 
me de Merteuil y Valmont, conforman la trama central del relato. Ellos son los verdaderos motores de una acción que no progresa sino por las decisiones que toman.

Para: Baudelaire, Madame de Merteuil, que le parece la verdadera conductora del juego y del relato, es un "Tartufo hembra, un Tartufo de costumbres, Tartufo del siglo XVIII". Ella es extraordinariamente lúcida, tiene la conciencia de su "métier". En la carta LXXXI, expone el lento y paciente trabajo que hizo de ella una "Eva satánica": todo su vocabulario traduce el deseo y la fuerza de ser, como lo explica Malraux en su Laclos, "Un personaje dueño, un instante, de su des tino".

En cambio Valmont no es más que el hombre que ella guía a distancia.

Laclos emprende en Les liaisons dangereuses la pintura reveladora de un comportamiento humano (el libertinaje), símbo lo de una sociedad en declinación (1a aristocracia), que desen mascara la verdadera naturaleza de las relaciones sociales (hí pocresia, convenciones, conformismos).

El juego de los libertinos destruye la vida de los personajes normales, pero al mismo tiempo los condena a los dos héroes al fracaso: su ausencia de sentimientos los obliga a re nunciar a una vida común. Así, arruinando los "prestigios de esta mitología de la inteligencia" (Malraux, Laclos), Laclos afirma que la vida es más fuerte que el sistema que la niega.

Se publica la novela y el destino de Laclos se dibuja: se vuelve un Valmont. (Es un hábito juzgar a los escritores se gín sus héroes. ¿Molière es un Tartufo o Racine es un Nerón?).

Desde la aparición de Les liaisons dangereuses, se nota cierta tendencia del público a juzgar a Laclos según sus perso najes, "Porque pinta monstruos, se ve que él es uno de ellos", dicen sus criticos.

En su Dernier Tableau de Paris, publicado en Londres en 1794, su autor Peltier ve en él "el hombre más profundamente pervertido del siglo, el héroe de los anales del libertinaje."

A Peltier, que lanza el anatema sobre Laclos en Londres, le hace eco Mme. Rol and en París.

$Y$ he aquí, en efecto, que la Revolución que modificó el 
destino de Laclos como el de la mayor parte de los franceses, va también a marcar un viraje importante en los juicios sobre el autor de Les liaisons dangeruses y sobre su novela.

Como la crítica va a ser inflexible en un cierto sentido y por muy largo tiempo, es indispensable analizar, de la ma nera más objetiva,los hechos esenciales de la acción de Laclos durante la Revolución.

En su Elogio del cardenal de Bernis, Roger Vaillan pretende que Choderlos de Laclos tiene " su carrera militar, poli tica y mundana, destrozada por haber escrito Les liaisons dangereuses".

Ahora bien, en el plano militar, Laclos, oficial de una armada técnica, la artilleria, ha tenido antes como después de su libro, una carrera sin brillo, a pesar de sus notas excelentes.

Si fue enviado en castigo a Metz el 11 de mayo de 1786, fue a causa de la publicación, no de su novela sino de su Elogio a Vauban, obra que era, en realidad, una apasionada crítica sistemática a la técnica de las fortificaciones del mariscal.

Por otra parte, es el éxito de Les liaisons dangereuses quien abrió a Laclos, en París, los salones.

Hasta 1782 él no había frecuentado más que la aristocrạ cia de provincia. En fin, son sobre todoestos sucesos mundanos, sumándose a la influencia de las logias masónicas, los que determinaron a los amigos de Laclos presentarlo al Duque de Or léans, Gran Maestre de todas las logias de Francia. Nuestro autor pertenecía a la logia del regimiento de Toul-Artilleria, y en París es admitido en la logia "La Candeur" donde se encon traban muy especialmente los hombres devotos de Felipe de orléans.

Peroes el vizconde de Noailles quien 10 introduce en la int imidad del Palais-Royal.

En octubre de 1788, Laclos es nombrado secretario de los comandantes del príncipe. ¿Cómo era este príncipe?: hombre de placeres, inteligente, pero de una negligencia peligrosa, y en él se buscará vanamente encontrar las cualidades tácticas o estratégicas de un Valmont, aún "obeso y viejo", según la ex- 
presión más pintóresca que fue empleada por el crítico Dard. (En todo lo que me refiera a Dard, corresponde a su libro Laclos, Ed. Perrin).

En las vísperas de la Revolución, el Palais-Royal se vuelve un centro de intrigas, el lugar avanzado del descontento, donde se elabora una oposición sistemática a la corte y al rey.

Los informes más diversos dan cuenta, luego, que Laclos se vuelve uno de los hombres más escuchado por Felipe.

Después de las jornadas del 5 y 6 de octubre de 1789, Laclos acompaña a Londres al Duque de Orléans a su semi-exilio. Permanece alli desde el 14 de octubre de 1789 hasta el 10 de julio de 1790 .

Vuelto miembro de la sociedad de los Jacobinos, redacta el Diario de los amigos de la Constitución, a partir del 21 de noviembre de 1790. Presenta su renuncia al Club el 17 de julio de 1791 , a continuación de los sangrientos incidentes del campo de Marte.

Es elegido comisario de la Municipalidad de París el 10 de agosto de 1791 y el 29 de agosto de 1792, Danton lo nombra comisario del poder ejecutivo.

Es con este título que asistirá a los preparativos de la batalla de Valmy.

Es arrestado el 31 de marzo de 1793 y puesto en libertad el 10 de mayo por la intervención de su amigo Alquier, pre sidente del Comité de Seguridad General.

En este momento procede a hacer experiencias sobre las cadenas huecas que ha inventado. Arrestado de nuevo el 5 de noviembre de 1793, no será liberado hasta el 3 de diciembre de 1794 .

Enseguida es nómbrado Secretario General de Hipotecas antes que el Primer Cónsul lo restablezca en su grado de general de brigada, y en la artillería.

De este análisis tan seco, ¿cuáles son los elementos que debemos retener?

En principio las jornadas de octubre de 1789. Lós enemi gos del Palais-Royal acusaron al duque de Orleáns y a Laclos de haber organizado la marcha del pueblo de París sobre Versai. 
1les. Según rumores descontrolados, se habia visto a Laclos, disfrazado de mujer, excitar a los grupos de manifestantes.

Ahora bien, el proceso de Chatelet, instituído para establecer las responsabilidades en este "affaire", no demostró de una manera cierta la participación directa de Laclos en este motín. Todos los testimonios son dudosos o muy reticentes.

Después de la detención del rey en Varennes, la Asamblea Constituyente entrega un decreto que declara inocente indirec tamente a Luis XVI, el 15 de julio de 1791. Ese mismo dia, según Mathiez en sus Annales de la Révolution, Laclos propone a los jacobinos firmar una petición contra el rey, considerando como que el rey ya había abdicado. Dice: "Si la Asamblea puso al rey fuera de causa, es porque ella no está bastante instruída sobre la opinión popular."

Sostenido por Robespierre y Danton, después de una entre vista con Laclos para poner a punto la táctica, se propone el establecimiento de un "consejo de prohibiciones". Y como por azar, ese mismo día el duque de Orléans se hace admitir en el Club de los Jacobinos.

El principio de la petición, verdadero plesbicito, en vista de una consulta de la nación sobre el rey, es adoptado por el club, un poco bajo la presión de manifestantes variados del Palais-Royal.

La petición es releída y firmada al otro día.

¿Cuál es el papel de Laclos en este "affaire"?

Si uno cree en uno de sus biógrafos, Dard, el autor de Les liaisons dangereuses, en este caso como en todos los otros, condujo todo con sugenio, tirando los hilos de las marionetas detrás del bastidor, en beneficio del duque de Orléans, para satisfacer su ambición.

Esta explicación de los móviles y de los actos por la ambición, es, por otra parte, clásica en todos los historiadores y cronistas de este periodo que no tiene más que una simpa tía fuertemente moderada para la Revolución.

Hay un testimonio contemporáneo que acusa directamente a Laclos. Brissot cuenta en sus Memorias cómo Laclos le ha for zado la mano para obligarlo a redactar la famosa petición $\bar{y}$ 
más precisamente para introducir alli la frase que permitía "proveer al reemplazo de Louis XVI" por "todos los medios cons titucionales", es decir, para una regencia en beneficio del du que de Orléans, porque los condes de Artois y de Provence ya habían emigrado.

¿En qué medida se le debe tener fe? Brissot "el más cán dido de los republicanos", según la opinión de Dard o "el más intrigante y poco escrupuloso". del cual habla Mathiez.

Lo que es seguro es que este mismo Brissot era un orlea nista $y$ que en sus Memorias hace recaer sobre los otros las résponsabilidades enojosas.

Ninguno de los grandes historiadores de la Revolución parece considerar a laclos como un personaje de primer plano.

Algunos hablan de él como de un "factotum" de Felipe de Orléans. En cuanto a Mathiez no lo nombra ni una sola vez en su obra La Révolution française.

Laclos escribe el 12 de agosto de 1791: "Declaro que re tirándome de la sociedad sesionante de logs jacobinos, no he pretendido jamás ser de otra. He querido solamente en estos tiempos donde la opinión sobre las personas varía de una manera muy asombrosa, aislarme enteramente y atenerme a los princi pios que no varian jamás."

Gracias a amistades siempre diligentes, activas, en par ticular las de Danton y de José Servan, Laclos no desapareció completamente de la escena. Por ejemplo, organizó en Chalons siete batallones de federados.

Su nominación como gobernador de los Establecimientos franceses de las Indias el 28 de noviembre de 1791, a pesar de que él estaba en la armada de Servan, es sin duda una maniobra de sus amigos para protegerlo de las persecusiones.

Es éste, en efecto, el momento en que los robespierristas acusan a Danton de orleanismo y donde Robespierre, él mismo, ve que le hacen el mismo reproche sus adversarios.

Pero un acontecimiento anticipa la partida proyectada. La traición de Carlos Francisco Dumouriez, triunfador en Valmy, que arrastra con él al duque de Chartres, provoca una 1lama anti-orleanista $y$, en consecuencia, el arresto de Laclos el 31 de marzo de 1793. Está encarcelado desde el $1^{\circ}$ de abril, 
pero gracias a la intervención de un amigo, es liberado y pues to en estado de arresto domiciliario el 10 de mayo.

Es entonces autorizado, gracias a su amigo Gaspard Monge, ministro de Marina, a experimentar ciertas balas de cañón huecas de su invención, destinadas a tirarlas contra los navíos. Estos proyectos de experiencias no fueron extraños a su excarcelación. Excarcelación provisoria, desde luego, porque es de nuevo encarcelado el 5 de noviembre de 1793, con la caída de los girondinos.

Esta es la última ofensiva de los orleanistas, aunque Felipe Igualdad es guillotinado el 7 de noviembre de 1793, y Laclos espera subir a la guillotina, como lo testimonia una carta a su mujer del 19 Germinal año II.

¿Por qué Laclos escapó a la pena capital? Hay solamente hipótesis. Dard pretende que "es la protección de Danton que lo salvó al principio". Es muy posible, porque es en la víspera de la ejecución de Danton que escribe la carte del 19 Germi nal.

Pero Danton muere; el problema sigue el mismo. Aunque, después de esa ejecución, el régimen de la prisión se suaviza para Laclos que va a estar, regularmente, en comunicación con su esposa a partir del 11 floral año II (mayo de 1794).

¿Cuál es la repuesta?: nuestro autor, prácticamente ais 1 ado y retirado de la vida política después de la renuncia de los jacobinos, fue sostenido en la sombra por fieles amistades: la de José Servan, la de Alquier, la de Lacombe de SaintMichel, y aún si se cree en el Almanaque de las prisiones (de 1794), Laclos encarcelado permanece en relación con el Comité de Salud Pública y esto lo volvía sospechoso a los ojos de los otros detenidos.

En la sucesión rápida de los acontecimientos después de la proclamación de la república, jamás él tuvo un papel de prí mer plano $y$, por lo tanto, se ha debido juzgar insuficientes las cargas que pesaban sobre él.

Los últimos meses de su detención, después de la muerte de Robespierre, no fueron terribles: si se consideran los datos, el tercero de sus hijos, Charles, "el niño de la liberación" como lo llama Dard, nacido el 4 de junio de 1795, fue concebido en septiembre de 1794 , tres meses antes de la liber- 
tad de su padre.

Tales son los hechos. ¿Y su novela?

Dard llama a Les liaisons dangereuses, "la novela de un ambicioso". Pero la ambición de Laclos, si la tuvo, no creó una novela que es una obra maestra; tal vez el éxito de esta novela es quien ha podido despertar justamente la ambición de Laclos,

Muchos oficiales en el siglo XVIII consagraban sus ocios a la literatura (el caballero de Chatelux, que será acadé mico, Rouget de Lisle, Carnot).

"La manía de los militares por las ocupaciones literarias es uno de los inconvenientes unidos al proceso de la lite ratura" dice el crítico Grimm el 1 de noviembre de 1761 , y vuelve constantemente sobre el tema en diciembre de 1764 y en febrero de 1765.

Es el mismo caso de un joven oficial de artillería que se llama Bonaparte. Imaginemos que él haya escrito una obra ma estra; no pretendemos que la tal obra le haya, sido dictada por la ambición.

¿Cómo si fuera suficiente ser ambicioso para escribir Les liaisons dangereuses!

¿Y por qué a Laclos, ambicioso, le había vastado un libro únicamente?

Raramente un libro habrá determinado de una manera tan precisa la orientación de la vida de una autor. El brillo provocado por su obra pudieron volverlo ambicioso pero no de la manera maquiavélica y sombría de la que se habla. Instalado por sus amigos aristócratas en las primeras habitaciones del Palais-Royal, él pudo esperar interpretar un papel de primer plano en la vida política del país para el caso è que su maes tro obtuviera la regencia o, aún, el trono.

Ensayemos de retroceder hasta lo que pudo ser la mentalidad de un Laclos. Pertenecía a una familia muy honorable pero de la pequeña nobleza. Gracias a estudios muy sólidos es re cibido como aspirante a la Escuela de Artillería de La Fere: va, pues, a servir en un arma técnica.

Al azar de sus guarniciones, reencuentra oficiales de otras armas que han podido, ellos, llegar a coroneles a la 
edad en que Laclos es teniente o capitán. ¿Hay resentimiento o amargura en él? Es posible, pero no es absolutamente cierto porque lo vemos unido a los más grandes nombres de la aristocracia: los Ségur, los Noailles...

Se ha querido hacer de Les liaisons dangereuses un panfleto contra la nobleza y esa es una opinión bien estrecha.

A los 47 años, Laclos está casado, padre de dos hijos todavía jóvenes; y este casamiento mismo dio lugar a interpretaciones fantásticas, aun cuando los hechos son de una extrema simplicidad.

Dard, fundándose en pretendidas confidencias con el yerno de Laclos, a Arsène Houssaye, afirma que nuestro autor ha obrado "friamente y ambicioso se complace en desafiar el obstáculo", seduciendo a Mlle. Duperré.

¿Cuál es la verdad? En 1783 Laclos, con 42 años, encuen tra en el salón de Mme. Duperré a una joven de 18 años, alegre e inteligente, que amará fiel y profundamente toda su vida. ¿Qué hace aquí la ambición?

E1 amor recíproco, desde el comienzo, fue tan fuerte para que una jovencita de la mejor sociedad, a pesar de las resistencias de su familia, se case en 1784, con el hombre que no dejará de amar...

¡No es el casamiento de Valmont con Cécile, sino el de Saint-Preux con Julie!

A los 47 años, entonces, Laclos, padre de dos niños y devoto de su familia, no podía vivir sino de su sueldo de capi tán y algunas rentas de su mujer.

Seis mil libras de salario, suplementarias, en el PalaisRoyal y una vivienda no eran para desdeñar, sin hablar del interés que puedan presentar las funciones de secretario del primer príncipe de sangre. Es inúltil imaginar una ambición frenética en Laclos para comprender su decisión de entrar al servicio del duque de Orléans, del cual por lo demás, la popularidad era muy grande.

Laclos es un espíritu cultivado, muy atento a las corrientes de su época y abierto a las ideas nuevas en política. El ideal para él mismo como para la mayor parte de sus contemporáneos, es una monarquía constitucional de tipo inglés: toda 
su conducta política lo prueba.

Que haya pensado en su príncipe como regente o como rey, esto es muy natural. Y por lo mismo, se comprende que fue sinceramente jacobino, en una época en que se era jacobino y monarquista liberal y donde nadie todavía pensaba en la Repú blica, aún Robespierre, y que él era sinceramente orleanista, en una época en que el orleanismo representaba la oposición a la adhesión a la monarquía real ultra. (Los jacobinos guardan su nombre de Amigos de la Constitución; es, solamente, el 21 de septiembre de 1792, después de la abolición de la realeza, que ellos tomarán el título de "Sociedad de los Jacobinos, amigos de la libertad y de la igualdad").

No tiene nada de maquiavélico esto que no excluye las finezas tácticas y las maniobras, clásicas en política y sobre todo en periodo revolucionario.

Que Laclos haya sido un demócrata sincero, pero moderado y razonable, muy "filósofo del siglo XVIII", lo demuestran también los ataques de los cuales fue objeto de parte de los extremistas de los dos extremos.

El es la cabeza de turco del partido del rey y Rivarol compone en su honor una parodia de Fedra. En un fragmento se escucha esto:

Mirabeau:-¿Quién lo hubiera creído? Laclos es jefe de la confä bulación.

Barnave:-¿Cómo?

Mirabeau:-El príncipe lo ama y yo no puedo dudar...

Este enemigo de las artes ha hecho elección de un au tor.

Y Laclos ha encontrado el camino de su corazón.

Barnave:-;Cielos!... ¿Laclos?

Mirabeau: - Ah ! dolor todavía no probado.

Esta parodia aparece publicada en el diario "Actes des apôtres". En el mismo diario, un redactor propone 11amar a la calle du Renard, rue de Laclos.

Pero cuando la ironía deja paso a la cólera, se escriben las injurias más groseras. En cuanto al otro, son más discretos en los ataques y las calumnias, pero son más peligmsos 
porque envian a Laclos a prisión.

Según el "Moniteur universel" del 5 de abril de 1793, es Robespierre el joven que reclama la prisión de Laclos. El no saldrá de prisión sino después de la ejecución del "Incorruptible", con aquellos diputados girondinos que tuvieron la suerte de escapar a la guillotina.

Todos estos enemigos están de acuerdo en identificar a Laclos con su héroe Valmont para atribuirle su inmoralidad y sus vicios.

Sin embargo, su obra fue un éxito total. Y para juzgar exactamente su valor, basta estudiar su influencia en la literatura. Tomaremos solamente el período anterior a la Revolución. Recordemos que la novela fue publicada en 1782 .

Los autores más diversos imitan, en sus obras, el título de la de Laclos: son más de diez.

Muchos autores dramáticos explotan el tema de Les liaisons...: Robineau, Le Danger de liaisons, 1783; Bievre, Le Séducteur, 1783; M. de la Chebeaussiere, La Confiance dangereuse, 1784; Mme. de Montesson, La Contesse de Chazelle, 1785; Collin, L'Inconstant, 1786; Bodard, Pauline et Valmont, 1787, etc.

Los poetas también encuentran tema en el libro: "El Mer cure" del 13 de junio de 1782 publica una Epístola a M. Dussault, traductor de Juvenal, donde se la-nombra a la Merteuil. Cierto Jean-Louis Laya escribe: Los últimos momentos de 1a presidenta de Tourval al vizconde de Valmon, acompañados de una carta de Dido a Eneas.

Los coleccionistas de estampas pueden pedir, a domicilio, los grabados que representan a los héroes de Les liaisons dangereuses, importados de Inglaterra.

Como vemos, el autor y su novela tuvieron distintos des tinos durante la Revolución. Laclos fue el prisionero y se lo tildó de ambicioso. Su obra: el éxito total.

Exito que siguió durante los siglos y que hoy, casi en el siglo XXI, brilla gracias al cine. La industria norteame ricana produjo una adaptación de Les liaisons dangereuses (antes hubo una memorable versión fílmica francesa con Gérard Phi lippe y Jeanne Moreau) gracias a una pieza teatral estrenada en Browdway en 1986. 
El ambiente es el suntuoso de los palacios de la aristo cracia francesa en los años anteriores a la Revolución de 1789, tiempos en que importan más las maneras que las intencio nes; en que vizcondes y marquesas llenan sus horas vacias con intrigas y juegos amorosos que revelan ansias de poder; tiempos en que el cinismo y la crueldad son motores de oscuras estrategias que parecen servir de entretenimiento para paliar los ocios cortesanos, aunque en el fondo de estas maniobras, siempre jugadas con los modos elegantes y artificiosos que la nobleza impone, se descubra el sombrío rostro de la decaden cià.

Las intenciones son las que examina el director de esta película, y examinándolas se asoma a algunos abismos de la condición humana hasta llegar a ese punto en que la codicia del poder termina vencida por la fuerza de los sentimientos.

Por eso están tan bien retratados los seres humanos. Por eso las cámaras se asoman a los rostros de los actores, alli donde pueden descubrir sutilmente crueldades y flaquezas, donde apresarán el cinismo y la mezquindad que los anima, pero también la fuerza ingobernable de la genuina émoción.

Otro director, Milos Forman, atraido también por el libro de Laclos, filma una nueva adaptación titulada Valmont. iTenemos Laclos por mucho tiempo! Esa es la vigencia de 1a. obra maestra.- 
VAILLAND, Roger, Laclos par lui-même, Le Seuil.

VERSINI, Laurent, Laclos et la tradition, Klincksiek.

DARD, E., Laclos, Perrin.

SEYLAZ, J.L., Les liaisons dangereuses et la creation romanesque chez Laclos, Droz.

MALRAUX, André, "Laclos", en Tableau de la litt. Française. XVII - XVIIIe. siècles, Gallimard.

BAUDELAIRE, Charles, Notes sur L.D., O.C. de B., Bibl. de la Pléide. 